\title{
CORRESPONDENCE
}

\section{Annuities-certain at linearly decreasing rates of interest}

The Editor,

The Fournal of the Institute of

Actuaries Students' Society

13 May 1948

Sir,

With reference to the article appearing under my name headed 'Annuities-certain at linearly decreasing rates of interest' in Vol. viI (1948), p. 253, an error has unfortunately been introduced into the heading of the second annuity column. This is not $a_{n}$ but $a_{n \mid}$ divided by the appropriate value of $\left[1+\cdot 08175\left(n^{2}-1\right) h\right]$.

It may be of interest to members to observe that since this note went into print a similar investigation has been carried out for $s_{\bar{n}+1}^{\prime}-I$, and I find that exactly the same empirical formula gives equally good results for that function.

With $v^{\prime n}$ obtained by differencing the values of $a_{n}^{\prime}$ we therefore have available a fairly simple method of $(a)$ calculating Sinking Fund premiums based on a combination of an interest rate $i$ and a form of probability that such rate will be realized in year $t$; and (b) carrying out a prospective valuation of Sinking Fund business on the same basis, allowing in successive valuations automatically for the rate $i$ having actually been realized in the intervaluation periods.

Finally, I would add that it is recognized that the best results for different values of $i$ and $h$ are given by varying slightly the factor ${ }^{08} 175$. This value, however, was selected as it appeared on a broad basis to give the most satisfactory general results, and the extent of the percentage error introduced over a period of even I00 years is such that variation of 08175 is not likely to be really worth while.

Yours faithfully,

E. M. THOMAS 